\title{
CORRIGENDUM
}

\section{In vivo expression of an aberrant MYB-GATA1 fusion induces leukemia in the presence of GATA1 reduced levels}

E Belloni, D Shing, C Tapinassi, A Viale, P Mancuso, O Malazzi, E Gerbino, V Dall'Olio, I Egurbide, MD Odero, F Bertolini and PG Pelicci

Leukemia (2011) 25, 1922; doi:10.1038/leu.2011.241

Correction to: Leukemia (2011) 25, 733-736; doi:10.1038/leu.2010.317

The authors apologise for any inconvenience caused.

Since the publication of this paper, the authors have noticed that one of the author names was incorrectly listed as P Giuseppe Pelicci. The correct name is shown above. 